\title{
Efeitos da exposição pré-natal e pós-natal ao etanol no córtex cerebral de ratos: um estudo do neurópilo
}

\section{Effects of prenatal and postnatal ethanol exposure in the cerebral cortex of rats: a study of neuropil}

Márcio Sousa Jerônimo'; Nicodemos Teles de Pontes Filho²; Mário Ribeiro de Melo Júnior ${ }^{3}$

\begin{tabular}{|c|c|}
\hline & \\
\hline $\begin{array}{l}\text { Etanol } \\
\text { Neurópilo } \\
\text { Desenvolvimento } \\
\text { Síndrome do alcoolismo } \\
\text { fetal (SAF) }\end{array}$ & $\begin{array}{l}\text { Introdução: Exposição pré-natal ao etanol é freqüentemente associada a microcefalia e atraso na migração } \\
\text { celular. O mecanismo pelo qual o etanol induz seus efeitos no desenvolvimento do sistema nervoso não } \\
\text { é muito bem entendido. Objetivos: Avaliar o efeito da exposição crônica ao etanol sobre o córtex visual } \\
\text { de ratos durante seu desenvolvimento. Material e método: Ratos Wistar provenientes do acasalamento } \\
\text { de } 30 \text { fêmeas, divididos nos grupos etanol }(n=10)-3 \mathrm{~g} / \mathrm{kg} / \text { dia - e controle }(n=10) \text {, foram utilizados } \\
\text { nesse experimento. Os ratos foram perfundidos e o encéfalo, dividido em três partes: anterior, médio e } \\
\text { posterior. Os cortes obtidos do fragmento posterior foram expostos à rotina histológica e submetidos } \\
\text { a diferentes técnicas de coloração. Na análise estatística foi utilizado o teste } t \text { para comparar os pesos } \\
\text { encefálicos e corporais. Considerou-se como nível de rejeição de hipótese nula um valor de } p<0,05 \text {. } \\
\text { Resultado: Houve redução de peso cerebral em diferentes períodos analisados, além de ectopia e heterotopia } \\
\text { neuronal. Não se observou deposição de fibras. Discussão/conclusão: O etanol atua de maneira negativa } \\
\text { no desenvolvimento dos ratos, incluindo alterações na migração neuronal e microcefalia. Essas alterações } \\
\text { podem ajudar a explicar as disfunções relatadas na síndrome do alcoolismo fetal (SAF). }\end{array}$ \\
\hline
\end{tabular}

\section{abstract}

Background: Prenatal exposure to ethanol is frequently associated with microencephaly and delayed cell migration. The mechanism by which ethanol affects the development of the nervous system is still not fully understood. Objective: To evaluate the effect of chronic exposure to ethanol on the visual cortex of rats during their development. Material and method: Wistar rats, born from the mating of 30 females, were divided into two groups: those exposed to ethanol $(\mathrm{n}=10)-3 \mathrm{~g} / \mathrm{kg} /$ day - and a control group $(\mathrm{n}=10)$. The rats were perfused and brain was divided into three parts: anterior, middle and posterior. Slices taken from the posterior fragment were subjected to histological analysis routine and different staining techniques. A statistical analysis was carried out using t test to compare brain and body weight. A value $<0,05$ was considered a rejection of null hypothesis. Result: There was a reduction of brain weight in different analyzed periods. There were no fiber deposits. Ectopia and neuronal heterotopia were observed. Discussion/conclusion: Ethanol has a negative effect on the development of rats, including alterations in neuronal migration and microencephaly. These alterations may help to explain some of the dysfunctions reported in patients with fetal alcohol syndrome (FAS). key words

Ethanol

Neuropil

Development

Fetal alcohol syndrome

(FAS)

1. Graduado em Biomedicina pela Universidade Federal de Pernambuco (UFPE); Laboratório de Imunopatologia Keiso Azami (LKKA) da UFPE.

2. Professor Titular de Anatomia Patológica da UFPE; Laboratório de Imunopatologia Keiso Azami (LIKA) da UFPE.

3. Associação Caruaruense de Ensino Superior (ASCES); LIKA/UFPE.

Este trabalho, realizado no Setor de Patologia do LIKA/UFPE, é a monografia de conclusão de curso apresentada ao Centro de Ciências Biológicas da UFPE.

0 protocolo experimental desenvolvido no presente trabalho foi submetido e aprovado pela Comissão de Ética Animal do Centro de Ciências Biológicas (CCB) da UFPE (ofício 119/2003) e respeita os princípios éticos de experimentação animal do Colégio Brasileiro de Experimentação Animal (COBEA). 


\section{Introdução}

Nenhuma outra substância é objeto tão freqüente de investigação científica como o etanol, para o estudo tanto do seu efeito sobre o organismo humano quanto dos distúrbios funcionais a ele associados. Tal interesse é justificado pela multiplicidade de ações tóxicas sobre órgãos e tecidos que desencadeiam mecanismos lesionais associados a diferentes patologias $(10,17)$.

Vários trabalhos demonstram as ações nocivas do álcool nas etapas do processo de diferenciação celular, observando-se bloqueio de receptores para neurotransmissores ${ }^{(9,}$ 13), interferência no processo de mielinização $0^{(22,31)}$ e na formação e modelamento do axônio e dendrito ${ }^{(26)}$. Porém o estudo do neurópilo é praticamente ignorado.

O etanol, que é uma molécula simples, é rapidamente absorvido pelo trato gastrintestinal, sendo menos de $10 \%$ eliminados pelos pulmões e rins e o restante oxidado pelo corpo. Por ser hidrossolúvel, distribui-se praticamente por todos os tecidos intra e extracelularmente, variando apenas de acordo com a composição química desses ${ }^{(13)}$. Por ter pequeno peso molecular, o etanol cruza livremente a barreira placentária, atingindo concentrações sangüíneas mais elevadas no feto do que na mãe ${ }^{(28)}$. O efeito tóxico no feto é, portanto, muito mais exacerbado, uma vez que sua função hepática ainda não está totalmente desenvolvida(6).

\section{Objetivos}

\section{Objetivo geral}

Avaliar os efeitos da exposição ao etanol sobre a morfometria e a citoarquitetura do córtex visual de ratos durante o desenvolvimento cerebral por meio da histoquímica do neurópilo.

\section{Objetivos específicos}

- Realizar análise morfométrica comparativa medindo-se:

- peso encefálico e macroscopia do cérebro dos filhotes das ratas expostas ao etanol no período gestacional.

- Descrever as alterações histológicas do neurópilo do córtex visual, avaliando-se:

- disfunção migracional dos neurônios;

- distribuição das fibras de colágeno;

- arranjo das fibras elásticas;

- expressão dos glicosaminoglicanos (GAGs).

\section{Material e métodos}

\section{Animais}

Foram utilizados 20 ratos machos jovens (40 dias), da linhagem Wistar, provenientes do acasalamento de 30 fêmeas adultas sem parentesco, matrizes com 120 dias de vida e peso médio de $235 \mathrm{~g}$.

Os animais, oriundos da colônia do Biotério do Departamento de Nutrição do Centro de Ciências da Saúde da Universidade Federal de Pernambuco (UFPE), foram mantidos em ambiente com ciclo claro-escuro de 12 horas, com temperatura de $23 \pm 1{ }^{\circ} \mathrm{C}$, com sistema de exaustão, em gaiolas plásticas com grades metálicas (33 × $40 \times 17$ $\mathrm{cm}$ ) e com oferta de água filtrada ad libitum durante todo o experimento.

\section{Acasalamento}

Para o acasalamento foram colocadas em cada gaiola três fêmeas e um macho. A prenhez era confirmada pela identificação de células descamativas, muco gestacional e espermatozóides ao exame microscópico da secreção vaginal diluída em solução salina morna (microscópio Zeiss Standard 25,10x). Esse exame era executado diariamente por até três dias, no período matinal. Diante da negatividade do teste as fêmeas eram mantidas em repouso por três dias, reiniciando-se o acasalamento com outro macho.

Confirmada a prenhez, as matrizes foram separadas de acordo com o protocolo experimental, no máximo duas por gaiola, e ali mantidas até o 18을 dia de gestação. A partir deste período foram transferidas para gaiolas individuais até o final do aleitamento (25을 dia de vida dos filhotes).

No período compreendido entre o primeiro dia de prenhez e o último do aleitamento, as matrizes receberam ração comercial para animais de experimentação (Labina $\left.{ }^{\circledR}\right)$ e foram submetidas a dois tratamentos: administração diária de água filtrada e de etanol por gavagem, sempre entre as 7e 9 horas da manhã.

Os filhotes das matrizes assim tratadas originaram os dois grupos experimentais desse trabalho:

- grupo controle (C): constituído por ratos $(n=10)$ cujas mães $(n=15)$ receberam $3,8 \mathrm{ml}$ de água filtrada;

- grupo etanol (E): constituído por ratos $(n=10)$ originários de mães $(n=15)$ que receberam etanol $(3 \mathrm{~g} / \mathrm{kg} / \mathrm{dia})$.

A dose de etanol escolhida seguiu a concentração proposta por Ferreira et al. ${ }^{(12)}$. 
No terceiro dia após o parto, executou-se a sexagem, excluindo-se as fêmeas devido à conhecida influência dos hormônios sexuais femininos no metabolismo do álcool $^{(7)}$. Os filhotes machos de cada grupo experimental, gerados por diferentes matrizes, foram misturados entre si e mantidos em ninhadas de quatro a seis animais. Esses procedimentos foram adotados no intuito de eliminar a formação de grupos contendo apenas filhotes irmãos e de uma única mãe, excluindo-se a possibilidade de os resultados obtidos serem influenciados pela suscetibilidade individual. A padronização do tamanho da ninhada teve como objetivo eliminar a desnutrição induzida por grandes ninhadas durante a lactação(11).

As matrizes do grupo etanol (E) continuaram a receber álcool no período de aleitamento, que foi até o $25^{\circ}$ dia de vida.

Após o desmame os filhotes foram mantidos com a dieta padrão até o dia da perfusão.

\section{Perfusão e microtomia}

No dia da perfusão o peso encefálico foi aferido após a retirada do cérebro da caixa craniana e exclusão do bulbo olfatório, do nervos cranianos e do cerebelo, empregandose balança analítica (Zeiss, modelo Sartorius).

Aos 40 dias de vida os filhotes foram pesados e anestesiados, por via intraperitoneal, com solução aquosa contendo uma mistura de uretana a $10 \%(1 \mathrm{~g} / \mathrm{kg})$ e cloralose a $0,4 \%$ (40 mg/kg), de acordo com o peso corporal. Para a execução da perfusão procedeu-se à ampla abertura do tórax para exposição do coração. Após a injeção de $0,1 \mathrm{ml}$ de heparina (Liquemine ${ }^{\circledR}$ ) no ventrículo esquerdo, para evitar a coagulação sangüínea, introduziu-se na mesma região uma cânula de polietileno (por onde foram injetadas as soluções de perfusão) e, concomitantemente, fez-se a abertura do átrio direito. Dessa forma, tanto o sangue quanto as soluções de perfusão eram eliminadas por aquela abertura. Após o bloqueio da artéria aorta abdominal com uma pinça hemostática procedeu-se à perfusão com o auxílio de um compressor com pressão regulada em torno de $90 \mathrm{mmHg}$. Para a remoção do sangue e manutenção da integridade tecidual injetou-se, por meio de uma cânula, um volume de $100 \mathrm{a} 150 \mathrm{ml}$ de uma solução tampão salina de fosfato (PBS) $0,1 \mathrm{M}, \mathrm{pH}$ 7,2-7,4, contendo $0,9 \%$ por volume de $\mathrm{NaCl}$. A seguir perfundiram-se 150 a $300 \mathrm{ml}$ de formaldeído a 10\% diluído em PBS a 0,9\%, controlando-se a fixação do tecido pelo volume inoculado e a rigidez do pescoço e dos membros superiores. Após a retirada do cérebro, o mesmo foi colocado em formalina a $10 \%$ tamponada até a microtomia.
No momento anterior à microtomia, o encéfalo foi dividido em três partes, mediante dois cortes coronais, utilizando-se navalha para microtomia e uma lupa estereoscópica com ocular milimétrica (Olympus, modelo TCHM), obtendo-se três fragmentos que foram denominados posterior, médio e anterior.

\section{Procedimento histoquímico}

O fragmento posterior correspondia à região encefálica posterior, indo da porção voltada para lambda e para o cerebelo até 5,5 mm em direção à região anterior do cérebro.

O fragmento médio iniciava-se no bordo da superfície de corte voltada para o fragmento posterior, indo até outra superfície de corte distante $4,5 \mathrm{~mm}$, também voltada para a parte anterior do encéfalo.

Finalmente, o fragmento anterior era constituído pelo segmento iniciado no bordo da superfície de corte voltada para o fragmento médio e contendo o restante do encéfalo anterior.

Esse procedimento foi adotado para a obtenção de cortes histológicos coronais seriados do córtex posterior (fragmento posterior) correspondente à área visual. Os fragmentos médio e anterior foram armazenados para outros estudos.

Os fragmentos de cérebro selecionados foram fixados num período mínimo de 48 horas em formalina a 10\% tamponada e, em seguida, emblocados em parafina. A partir deles foram obtidos cortes histológicos com $4 \mu \mathrm{m}$ de espessura por meio de micrótomo horizontal Yamato Koki (Japão) e montados em lâminas histológicas albuminizadas. Os cortes obtidos foram previamente expostos à rotina histológica e submetidos a diferentes técnicas de coloração: hematoxilina-eosina (HE), para observação das características histológicas gerais; e tricrômico de Masson (TM), ácido periódico de Schiff (PAS) e Van Gienson (VG) para evidenciar, respectivamente, a deposição de colágeno, a expressão de GAGs e de fibras elásticas. Todos os protocolos experimentais foram desenvolvidos segundo Spicer ${ }^{(27)}$.

Os critérios utilizados na seleção das lâminas para as análises histológicas foram a integridade do corte, a boa marcação com os respectivos corantes e o reconhecimento dos limites do córtex, que foi realizado por comparação com um atlas estereotáxico(23).

Para a verificação da expressão de GAGs foi realizada uma comparação semiquantitativa das células PAS+ nos dois grupos experimentais, classificando a coloração em intensa (+++), moderada (++) e fraca (+). 
Para evidenciar a deposição de colágeno (TM) e o arranjo de fibras elásticas (VG), todas as áreas do córtex visual foram analisadas.

\section{Morfometria e estatística}

Imagens digitais foram capturadas das lâminas histológicas utilizando um sistema de videocâmera acoplado a um microscópio ótico (Olympus BH-2), já utilizado com sucesso em análises diagnósticas ${ }^{(21)}$. O sistema interativo utiliza o software Optimas ${ }^{\circledast}$ para o estudo da estatística e câmera digital CCBBN (Samsung) disponível no Departamento de Patologia da UFPE. Para análise estatística foi utilizado o teste $t$ para comparar os pesos encefálicos. Em todos os casos considerou-se como nível de significância para rejeição de hipótese nula um valor de $p<0,05$.

\section{Resultados}

A análise do peso encefálico aos 40 dias de vida demonstrou haver diferença significativa $(p<0,05)$ entre os dois grupos (Figura 1).

Microscopicamente foi observada uma desorganização neuronal da citoarquitetura do córtex cerebral do grupo etanol (Figura 2).

Não foram observados depósitos de fibras de colágeno e/ou elásticas na matriz extracelular nos grupos experimental e controle.

No que diz respeito à densidade do material PAS+, foram observadas diferenças entre os grupos por meio de análise semiquantitativa. A expressão de GAGs mostrou-se intensa (+++) em todo o córtex do grupo controle; no grupo etanol,

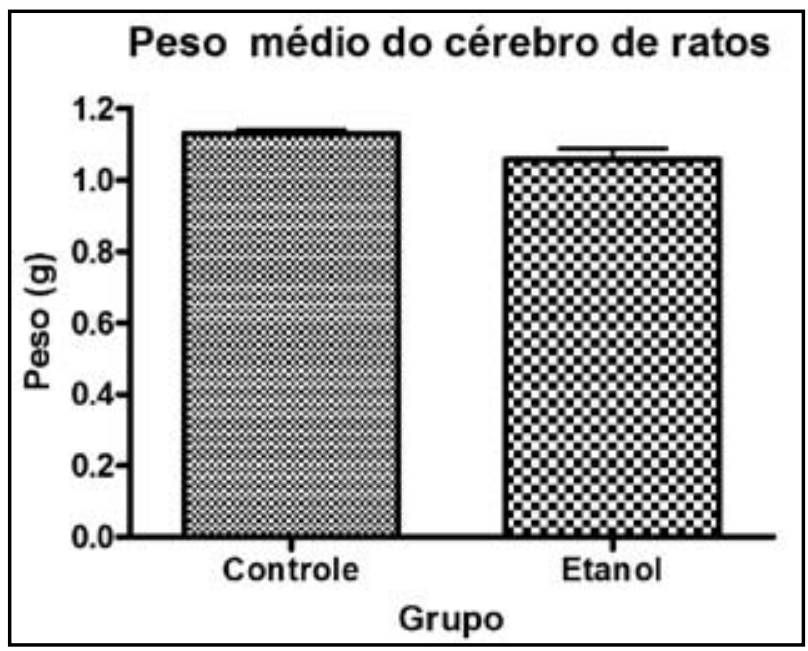

Figura 1 - Peso médio do cérebro de ratos mostrando diferença entre os grupos etanol e controle

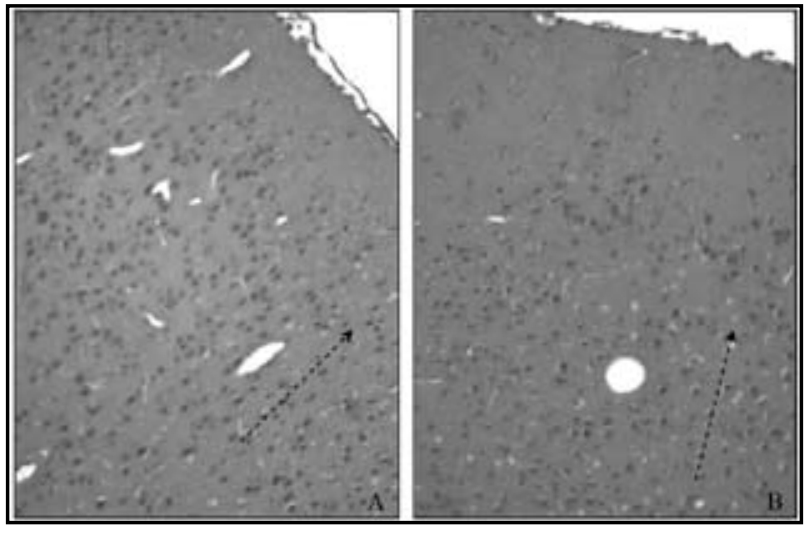

Figura 2 - Organização neuronal do córtex visual de ratos do grupo controle $(A) e$ irregularidade dos neurônios do grupo etanol (B) (HE, magnificação 100x)

moderada (++) na parte inferior e fraca (+) nas camadas mais superficiais do córtex, e, em alguns casos, apenas com a presença de grupo isolados.

\section{Discussão}

A microcefalia, tanto no alcoolismo experimental(28) quanto no humano(25), é a principal alteração encontrada. Miller e Potempa ${ }^{(20)}$, em trabalho semelhante ao nosso, explicam essa característica em animais com 90 dias de idade como uma alteração decorrente da redução da quantidade e do volume dos neurônios, que diminuiriam a massa do córtex cerebral pesado isoladamente.

As moléculas da matriz extracelular (MEC) podem estar estruturadas em fibras colágenas, reticulares e elásticas ou sob a forma de um complexo amorfo. Defeitos adquiridos do colágeno decorrem de agressões que perturbam o mecanismo pós-transducional de sua síntese ${ }^{(24)}$. Vários $\operatorname{estudos}^{(3,7,19,29)}$ demonstram que o etanol pode induzir a deposição de colágeno em diversos tecidos e órgãos, porém isso não foi evidenciado em nosso experimento. É possível que o etanol tenha alterado a distribuição das fibras de colágeno e elásticas, mas nossa técnica de marcação para essas fibras restringiu-se à análise por microscopia ótica; como no córtex do SNC normal a quantidade delas é mínima ${ }^{(15)}$ e só observada por microscopia eletrônica, acreditamos que se note alguma alteração utilizando-se essa técnica ou outras mais específicas de imuno-histoquímica ${ }^{(22)}$.

Segundo Champe e Harvey ${ }^{(8)}$, os GAGs, uma classe de compostos antigamente denominados mucopolissacarídeos ácidos ${ }^{(30)}$, estabilizam e sustentam os componentes celulares e fibrosos do tecido - já que geralmente se associam a proteoglicanos, formando grandes complexos na matriz 
extracelular, e por vezes a proteínas fibrosas da matriz, como o colágeno(2). Além disso, como componentes essenciais daquela, desempenham uma função importante na mediação das interações intercelulares( ${ }^{(24)}$. Assim, qualquer alteração na sua síntese pode prejudicar a migração celular, promovendo uma distribuição "desorganizada", como a observada no grupo etanol. A marcação PAS+ evidencia que os neurônios mais externos do córtex sofreram efeito maior do álcool e tiveram sua migração mais comprometida que os neurônios das camadas internas, gerados posteriormente e com menor tempo de exposição ao etanol.

\section{Conclusão}

Com relação ao efeito do etanol no desenvolvimento do cérebro de ratos podemos concluir que o nosso protocolo confirma os principais achados publicados na literatura, como microcefalia, com redução significativa da massa cerebral, e disfunção migracional dos neurônios, justificada aqui pela diminuição da expressão de GAGs no neurópilo do grupo etanol. Também constatamos que, ao contrário do que ocorre em outros tecidos e órgãos, na matriz extracelular do cérebro o álcool não tem a capacidade de induzir a deposição de fibras de colágeno e elásticas.

\section{Referências}

1. ABRAHAM, M. H. et al. Role of hydrogen boding in general anesthesia J Pharmacology Sci, n. 80, p. 719-24, 1991

2. ALBERTS, B. et al. Biologia molecular da célula. 3. ed. Porto Alegre: Artes Médicas, 1997.

3. ARAÚJO FILHO, J. L. Análise histomorfométrica do coração de ratos expostos indiretamente ao etanol no período perinal. 2003. Tese (Monografia de conclusão de curso) - Centro de Ciências Biológicas da Universidade Federal de Pernambuco, Recife, 2003.

4. BARRY, J. A.; GAWRISH, K. Direct NMR evidence for ethanol binding to the lipid-water interface of phospholipid biliayers. Biochemistry, n. 33, p. 8082-8, 1994.

5. BERMAN, R. F. et al. Prenatal alcohol exposure and effects of environmental enrichment on hippocampal dendritic spine density. Alcohol, v. 13, p. 209-16, 1996.

6. BRODY, T. Alcohol, nutritional biochemistry. 9. ed. London: Academic Press, 1998.

7. CARDOS-SILVA, C. D. Estudo histoquímico e morfométrico das alterações hepáticas em ratos expostos ao etanol e desnutrição crônica no período perinatal. 2003. Tese (Monografia de conclusão de curso) - Centro de Ciências Biológicas da Universidade Federal de Pernambuco, Recife, 2003.

8. CHAMPE, P. C.; HARVEY, R. A. Bioquímica ilustrada. 2. ed. Porto Alegre: Artes Médicas Editora, 2000.

9. CHEPKOVA, A. N. et al. Neotropic compound Lpyroglutamyl-D-alanine-amide restores hippocampal potentiation by exposure to ethanol in rat. Neurosci, n. 188, p. 163-6, 1995.

10. CRABE, J. C. Use of genetic analyses to refine phenotypes related to alcohol tolerance and dependence. Alcoholism, clinical and experimental research, n. 25, p. 288-92, 2001.

11. DELUCA, B. et al. Cortical and caudate spreading depression as indicator of neural changes induced by early malnutrition in rats. Activitas Nervosa Superior, v. 19, p. 130-1, 1977.

12. FERREIRA, T. A. et al. Effect of acute prenatal exposure to ethanol on the postnatal morphology of the prefrontal cortex in Wistar rats. Braz J Morphol Sci, v. 21, n. 2, p. 99-103, 2004.

13. GIL-MARTíN, E. et al. Effect of acute dose ethanol on dopaminergic and serotonergic system from rat cerebral cortex and striatum. Comp. Biochem Physiol, v. 113C, n. 3, p. 399-402, 1989.

14. HARDIN, G. G. Postmortem blood and vitreo humor ethanol concentrations in a fatal vehicle crash. Journal of Forensic Science, v. 47, n. 2, p. 402-3, 2002.

15. JUNQUEIRA, L. C.; CARNEIRO, J. Histologia básica. 9. ed. Rio de Janeiro: Guanabara-Koogan, 1999.

16. KORSTEN, M. A. Alcoholism and pancreatitis: does nutrition play a role? Alcohol Health \& Research World, v. 13, n. 3, p. 232-7, 1989.

17. LIEBER, C. S. Alcoholic liver disease: new insights in pathogenesis lead to new treatments. Journal of Hepatology, n. 32, v. 1, p. 113-28, 2000.

18. LINDI, C. et al. Effect of ethanol exposure on Xemopus embryo lipid composition. Alcohol Alcohol, v. 36, p. 388-292, 2001.

19. MELO-JÚNIOR, M. R. Estudo histológico e morfométrico do baço de ratos submetidos ao alcoolismo crônico nos períodos pré e pós-natal. 2001. Tese (Monografia de conclusão de curso) - Centro de Ciências Biológicas da Universidade Federal de Pernambuco, Recife, 2001.

20. MILLER, M. W.; POTEMPA, G. Number of neurons and glia in mature rat somatosensory cortex: effects of prenatal exposure to alcohol. The Journal of Comparative Neurology, v. 293, p. 92-102, 1990.

21. OBERHOLZER, M. et al. Methods in quantitative image analysis. Histoche Cell Bio., v. 105, p. 333-55, 1996.

22. ÖZER, E. et al. Effects of prenatal exposure on neuronal migration, neurogenesis and brain myelination in the mice brain. Clin Neuropath, v. 19, n. 1, p. 215, 2000.

23. PAXINOS, G.; WATSON, C. The rat brain in stereotaxic coordinates. 4. ed. California: Academic Press, 1998.

24. PEREIRA, F. E. L. Degeneração, morte celular e alteração no interstício. In: Brasileiro Filho, G. Bogliolo Patologia. 6. ed. Rio de Janeiro: Guanabara-Koogan, 2000. 
25. ROSENBERG, A. Brain damage caused by prenatal alcohol exposure. Science and Medicine, n. 4, p. 4250, 1996.

26. SCOTT, H. C. et al. Effect in uterus of ethanol exposure on the developmental of $\mathrm{LHRH}$ neurons in the mouse. Brain Res, n. 66, p. 113-28, 1992.

27. SPICER, S. S. Histochemistry in pathologic diagnosis. New York: Dekker, 1987.

28. STREISSGUTH, A. P. et al. Teratogenic effects of alcohol in humans and laboratory animals. Science, v. 209, n. 4454, p. 353-61, 1980.
29. VEIGA, R. K. A. Alterações imunomorfológicas no timo, baço e placas de Peyer durante a exposição pré e pósnatal ao álcool. 2003. Tese (Monografia de conclusão de curso) - Cetro de Ciências Biológicas da Universidade Federal de Pernambuco, Recife, 2003.

30. VIEIRA, E. C. et al. Química fisiológica. 2. ed. São Paulo: Atheneu Biblioteca Biomédica, 1995.

31. ZOELLER, R. T. et al. Limited postnatal ethanol exposure permanently alters the expression of m-RNAs encoding myelin basic protein and myelin-associated glycoprotein in cerebellum. Alcohol Clin Exp Res, n. 18, p. 909-16, 1994. 